\title{
Intermittent feeding induces compensatory growth of juvenile yellow mystus (Hemibagrus nemurus)
}

\author{
Karun Thongprajukaew ${ }^{1, *}$ and Somrak Rodjaroen ${ }^{2}$ \\ ${ }^{1}$ Department of Applied Science, Faculty of Science, Prince of Songkla University, Songkhla 90112, Thailand \\ 2 Department of Bioscience, Faculty of Sciences and Fisheries Technology, Rajamangala University of Technology Srivijaya, \\ Trang 92150, Thailand
}

Received 26 September 2016 / Accepted 23 December 2016

\begin{abstract}
Cyclical starvation and refeeding in order to induce compensatory growth were investigated in juvenile yellow mystus (Hemibagrus nemurus). The fish $(7.12 \pm 0.14 \mathrm{~g}$ initial body weight and $8.87 \pm 0.04 \mathrm{~cm}$ initial length) were starved for one (1DPW), two (2DPW), three (3DPW) or four (4DPW) days per week and otherwise fed ad libitum, while the control group was fed every day (no starvation, ODPW). The indoor experiments lasted six weeks and followed a completely randomized design ( 5 treatments $\times 3$ replications $\times 10$ fish per replication). Growth performance, feed utilization, specific activity of digestive enzymes, carcass composition and muscle quality were used to compare the treatment effects. The fish in the 3DPW group exhibited clear compensation for the reduced number of feeding days and had increased body weight towards the end of the experiment. However, this compensation was insufficient to match the specific growth rate in the control group that was fed to satiation daily. The 3DPW treatment also maintained feed utilization parameters, specific activities of protein-, carbohydrate- and lipiddigesting enzymes, carcass composition and muscle quality, relative to the ODPW control group. The remaining treatments gave some inferior characteristics when compared to 3DPW and 0DPW; the ranking of these feeding treatments was unexpected within the studied period. These findings suggest that cyclical starvation for three days per week (3DPW treatment) and refeeding could be used for rearing juvenile yellow mystus. The intermittent feeding schedule scheme is useful for labor management in the aquaculture production of yellow mystus. However, since partial compensatory growth was observed in the 2DPW and 4DPW groups, as indicated by the compensation coefficient, prolonged experiments on the accelerated growth rate should be conducted in further studies.
\end{abstract}

Keywords: Digestive enzyme / Feeding performance / Growth / Hemibagrus nemurus / Refeeding / Starvation

\section{Introduction}

Yellow mystus (Hemibagrus nemurus) is a river catfish found in most habitat types, but most frequently in large muddy rivers with a slow current and soft bottom (Kottelat, 1998). This species is distributed across South-East Asian countries including Thailand, Laos, Cambodia, Vietnam, Indonesia and Malaysia (Rainboth, 1996). Yellow mystus is usually marketed as fresh fish and also serves as a highly priced aquarium fish (Rainboth, 1996; Ng and Rainboth, 1999). Artificial spawning using the heteroplastic pituitary extract in combination with human chorionic gonadotropin (HCG) has been successfully developed (Thalathiah et al., 1988, 1992). It is widely used in culturing of economically important

\footnotetext{
* Corresponding author: karun.t@psu.ac.th
}

freshwater fish species in Thailand (Amornsakun et al., 1998). As yellow mystus is a relatively new species for intensive aquaculture, the optimization of practical protocols for commercial production is still incomplete.

Compensatory growth is characterized by a phase of accelerated growth, in terms of weight gain, following a period of restricted feeding (Nicieza and Álvarez, 2009). This phenomenon can be used to enhance growth and feed utilization in many fish species (Tian and Qin, 2003; Foss et al., 2009; Tian et al., 2010; Urbinati et al., 2014). Fish farmers can benefit from unchanged or even improved productivity, while the effort to feed the fish is reduced (Känkänen and Pirhonen, 2009). On comparing growth performances between periodically restricted access to food and unrestricted access, the results can vary widely with overcompensation, full, partial or no compensation (Ali et al., 2003). While such compensatory growth has been studied in 
several species, there is no prior study on the response of yellow mystus to periodic feed restrictions.

Either increased feed intake and/or improved feed efficiency is needed for faster growth, as in the compensatory growth of fish (Ali et al., 2003). The activities of digestive enzymes may help understand the responses in digestive machinery during physiological acclimatization (Chan et al., 2008; Furné et al., 2008; Abolfathi et al., 2012; Pujante et al., 2015), as well as help resolve nutritional problems under feed restrictions. Carcass composition and muscle quality are quality criteria relevant to human consumption, complementing information on mass growth rates (Jobling et al., 1994; Heide et al., 2006; Foss et al., 2009). The main purpose of this study was to assess the compensatory growth of yellow mystus, when subjected to periodic feed starvation and refeeding. The assessment was based on experimentally determined growth performance, feed utilization, specific activities of digestive enzymes, carcass composition and muscle quality.

\section{Materials and methods}

\subsection{Cyclical starvation and refeeding trial}

Juvenile yellow mystus $(7.12 \pm 0.14 \mathrm{~g}$ initial body weight and $8.87 \pm 0.04 \mathrm{~cm}$ initial length) were obtained from a private farm in Trang province, Thailand. The fish were acclimatized for 1 week in round fiberglass tanks ( $2 \mathrm{~m}$ diameter) with a $20 \mathrm{~cm}$ water level. They were fed twice daily (08.00 and $18.30 \mathrm{~h}$ ) to satiation with a commercial pellet diet (MN32; Lee Feed Mill PCL, Bangkok, Thailand) for carnivorous fish (containing $\geq 30 \%$ crude protein, $\geq 3 \%$ crude lipid, $\leq 8 \%$ crude fiber and $\leq 12 \%$ moisture as feed basis). Subsequently, screened fish with similar weight and length were randomly distributed to each aquarium $(90 \times 45 \times 42 \mathrm{~cm}$ with a $20 \mathrm{~cm}$ water level). Each aquarium had ten fish as a treatment group. In the feeding treatments, the fish were starved of feed for one day per week (1DPW), two (2DPW), three (3DPW) or four (4DPW) consecutive days per week, and fed ad libitum on the remaining days. No feed starvation was imposed in the control treatment (0DPW). Each aquarium was covered with black plastic to reduce stress due to feed starvation, and contained two hollow plastic tubes for concealment. The experiment was conducted for 6 weeks under a 12-h light/12-h dark cycle. The water was refreshed every other day by $20 \%$ replacement, and continuous aeration was supplied by air compressor pumps. The water quality parameters $\mathrm{pH}$ and temperature (PH500; Clean Instruments, New Taipei, Taiwan), and dissolved oxygen (DO500; Clean Instruments, New Taipei, Taiwan) were monitored using a water analyzer every week. Ammonia nitrogen (phenate method) was analyzed according to APHA, AWWA and WPCF (1998). The growth performance was monitored by recording weight and length at the end of the experimental period. Uneaten feed was collected $1 \mathrm{~h}$ after feeding (twice daily), dried at $60^{\circ} \mathrm{C}$ until constant weight, and the determined weight was used to calculate the feed intake (FI), the feed conversion ratio (FCR), and the protein efficiency ratio (PER). These parameters were based on the dry weight of diet consumed, and were calculated per individual fish. At the end of the feeding treatment trial (the last day of refeeding), all the fish were starved for $24 \mathrm{~h}$ and then sacrificed by chilling in ice. The fish preparation for sacrifice conformed to "Ethical Principles and Guidelines for the Use of Animals for Scientific Purposes (Sections 1.4 and 4.5.3)", National Research Council, Thailand. Liver, stomach, intestine and white muscle (under dorsal fin) were dissected, weighed and then kept at $-20^{\circ} \mathrm{C}$ until used. The whole fish carcass (body) was minced before determining its composition.

\subsection{Digestive enzyme studies}

\subsubsection{Extraction of digestive enzymes}

The frozen stomach and intestine were homogenized using a micro-homogenizer (THP-220; Omni International, Kennesaw, GA, USA) in $0.2 \mathrm{M}$ phosphate buffer at $\mathrm{pH} 8(1: 5, w / v)$. The homogenate was centrifuged at $15,000 \times g$, at $4{ }^{\circ} \mathrm{C}$ for $30 \mathrm{~min}$, the lipid layer on the surface was removed, and the supernatant was kept at $-20^{\circ} \mathrm{C}$.

\subsubsection{Protein concentration}

Determination of protein concentration was based on the method of Lowry et al. (1951). Bovine serum albumin (BSA) was used as the protein standard. The protein concentrations in the crude enzyme were used for quantifying digestive enzyme specific activities ( $\mathrm{Umg}_{\mathrm{mg}}$ protein ${ }^{-1}$ ).

\subsubsection{Determination of digestive enzyme activity}

Pepsin (EC 3.4.23.1) activity was assayed using casein as substrate according to Rungruangsak and Utne (1981). The specific activities of trypsin (EC 3.4.21.4) and chymotrypsin (EC 3.4.21.1) were assayed using $N$-benzoyl- $L$-Arg- $p$-nitroanilide (BAPNA) and $N$-succinyl-Ala-Ala-Pro-Phe- $p$-nitroanilide (SAPNA) as the substrates, respectively, as described in Rungruangsak-Torrissen et al. (2006). Amylase (EC 3.2.1.1) activity was determined based on Areekijseree et al. (2004) using soluble starch as substrate. Lipase (EC 3.1.1.3) activity was analyzed based on Winkler and Stuckmann (1979) using $p$-nitrophenyl palmitate as the substrate. Products of the five assayed enzymes were compared against standard $L$-tyrosine $\left(\mathrm{A}_{720}\right), p$-nitroanilide $\left(\mathrm{A}_{410}\right), p$-nitroanilide $\left(\mathrm{A}_{410}\right)$, maltose $\left(\mathrm{A}_{540}\right)$ and $p$-nitrophenol $\left(\mathrm{A}_{410}\right)$, respectively.

\subsection{Carcass composition}

The moisture, ash and protein contents were determined according to the standard method of AOAC (2005). The lipid content was extracted using ethyl acetate as described in Supannapong et al. (2008). Lipid/LBM (lean body mass) was calculated from the ratio of lipid to sum of protein and ash. All values are given as $\%$ on wet weight basis.

\subsection{Muscle quality}

\subsubsection{RNA and protein concentration}

The concentrations of RNA and protein were determined using Trizol reagent (Invitrogen, Carlsbad CA, USA) as described in Rungruangsak-Torrissen (2007). The extinction coefficients for RNA and protein used in the calculations

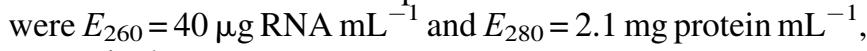
respectively. 


\subsubsection{Thermal transition characteristics of muscle protein}

Thermal properties including onset $\left(T_{0}\right)$, peak $\left(T_{p}\right)$ and conclusion $\left(T_{c}\right)$ temperatures of protein denaturation, and the transition enthalpy $(\Delta H)$, were studied using a differential scanning calorimeter (DSC7; Perkin Elmer, Waltham, MA, USA). Twenty milligrams of a defrosted muscle sample was placed in an aluminum pan, sealed, allowed to equilibrate at room temperature, and then heated with comparison against an empty reference pan. The thermal properties were recorded for temperatures from 35 to $95^{\circ} \mathrm{C}$, scanned at a rate of $5^{\circ} \mathrm{C} \mathrm{min}{ }^{-1}$. Muscle myosin, actin and sarcoplasmic protein were identified based on their thermal transition properties according to Skipnes et al. (2008).

\subsection{Statistical analysis and calculations}

The observed data are summarized as mean and SEM, and were analyzed using SPSS Version 14 (SPSS Inc., Chicago, USA). Duncan's multiple range test, with significance equated to $P<0.05$, was used to test the significances of differences between means. The calculation of growth and feed utilization parameters was as follows:

Weight gain $(\mathrm{WG}, \mathrm{g})=$ Final body weight $(\mathrm{g})$ - initial body weight $(\mathrm{g})$,

Condition factor $\left(\mathrm{CF}, \mathrm{g} \mathrm{cm}^{-3}\right)=100 \times[$ Live body weight $(\mathrm{g}) /$ total body length $\left(\mathrm{cm}^{3}\right)$,

Specific growth rate $\left(\mathrm{SGR}, \%\right.$ day $\left.^{-1}\right)=100 \times\left[\left(\ln W_{t}-\ln W_{0}\right) /\right.$ $\left.\left(t-t_{0}\right)\right]$

where $W_{t}=$ mean weight $(\mathrm{g})$ at day $t, W_{0}=$ mean weight $(\mathrm{g})$ at day $t_{0}$.

Hepatosomatic index $($ HSI, \% $)=100 \times[$ Wet weight of liver $(\mathrm{g}) /$ wet body weight $(\mathrm{g})]$,

$$
\mathrm{FI}\left(\mathrm{g} \mathrm{day}^{-1}\right)=F /\left(W_{0}+W_{1} / 2\right) \times\left(N_{0}+N_{1} / 2\right) t,
$$

where $F=$ dry feed fed $(\mathrm{g}), W_{0}=$ average initial body weight $(\mathrm{g}), W_{1}=$ average final body weight $(\mathrm{g}), N_{0}=$ initial fish number, $N_{1}=$ final fish number, $t=$ rearing period (day).

FCR $\left(\right.$ g feed g gain $\left.{ }^{-1}\right)=$ Dry feed fed $(\mathrm{g}) /$ wet weight gain $(\mathrm{g})$,

$\operatorname{PER}\left(\right.$ g gain g gain $\left.{ }^{-1}\right)=$ Wet weight gain $(\mathrm{g}) /$ protein intake $(\mathrm{g})$, Compensation coefficient $(\mathrm{CC})=\Delta T / \Delta C$, where $\Delta T=$ average $\mathrm{WG}$ in treatment group $(\mathrm{g}) /$ number of feeding days (day), $\Delta C=$ average $W G$ in control group $(\mathrm{g}) /$ number of feeding days (day).

\section{Results}

\subsection{Water quality}

The cyclical starvation and refeeding had no effects on the monitored water quality parameters $(P>0.05$, Table 1$)$. The $\mathrm{pH}$, temperature and dissolved oxygen were similar across the five feeding treatments. A significant decrease in ammonia nitrogen was only observed in the fish deprived for 4DPW relative to the ODPW control group.

\subsection{Growth performance and feed utilization}

Over the duration of the experiment, the counts of feeding days in the 0DPW, 1DPW, 2DPW, 3DPW and 4DPW groups were 42, 36, 30, 24 and 18 days, respectively. Compensatory growth, as observed by body weight, was observed in the fish deprived 3DPW (Table 2). The control ODPW and 3DPW treatments had no significant differences in total length, $\mathrm{CF}$, HSI, FI, FCR or PER, while the SGR was significantly decreased $(P<0.05)$ by the cyclical starvation and refeeding treatment. Starvation for 2DPW gave inferior growth performance relative to control, observed in all the above parameters. The fish deprived 1DPW had better growth performance than the 4DPW group. However, based on CC analysis, compensation ( $\mathrm{CC}>1.0)$ was clearly observed in the $3 \mathrm{DPW}$ group $(\mathrm{CC}=1.38)$, followed by the groups $4 \mathrm{DPW}$ $(\mathrm{CC}=1.20)$ and $2 \mathrm{DPW}(\mathrm{CC}=1.10)$, while the $1 \mathrm{DPW}$ group was inferior $(\mathrm{CC}=0.86)$ (Fig. 1).

\subsection{Digestive enzymes}

Some aspects of physiological acclimatization in relation to intermittent feeding are depicted in Figures 2 and 3. There were no differences in pepsin specific activity across the five feeding treatments (Fig. 2a). Fish starved 4DPW had significantly higher trypsin specific activity than the other groups (Fig. 2b). Chymotrypsin specific activity was highest in the 4DPW group, and also 1DPW and 2DPW had elevated activities relative to ODPW and 3DPW (Fig. 2c). The specific activity of amylase was unaffected by the feeding treatments (Fig. 3a). The lipase specific activity was similar in the 0DPW, 3DPW and 4DPW groups, while it had lower activity in the 1DPW and 2DPW groups (Fig. 3b).

Table 1. Water physicochemical properties during juvenile fish rearing. The analysis was performed in triplicate once every week.

\begin{tabular}{|c|c|c|c|c|c|c|c|}
\hline Parameter & ODPW & 1DPW & 2DPW & 3DPW & 4DPW & SEM & $P$ value \\
\hline $\mathrm{pH}$ & 7.78 & 7.78 & 7.81 & 7.71 & 7.75 & 0.02 & 0.878 \\
\hline Temperature ( $\left.{ }^{\circ} \mathrm{C}\right)$ & 26.31 & 26.32 & 26.35 & 26.33 & 26.30 & $<0.01$ & 0.945 \\
\hline Ammonia $\left(\mathrm{mg} \mathrm{L}^{-1}\right)$ & $0.29^{\mathrm{a}}$ & $0.28^{\mathrm{a}}$ & $0.30^{\mathrm{a}}$ & $0.26^{\mathrm{ab}}$ & $0.22^{\mathrm{b}}$ & $<0.02$ & 0.122 \\
\hline
\end{tabular}

Differences between means were tested with Duncan's multiple range test.

Different superscripts in the same row indicate a significant difference $(P<0.05)$. 
Table 2. Growth performance, organ indices and feed utilization of yellow mystus reared under various cyclical starvation and refeeding cycles.

\begin{tabular}{|c|c|c|c|c|c|c|c|}
\hline Parameter & ODPW & 1DPW & 2DPW & 3DPW & 4DPW & SEM & $P$ value \\
\hline Final total length $(\mathrm{cm})$ & $11.99^{\mathrm{a}}$ & $11.33^{\mathrm{ab}}$ & $11.57^{\mathrm{ab}}$ & $11.55^{\mathrm{ab}}$ & $10.80^{\mathrm{b}}$ & 0.19 & 0.046 \\
\hline Specific growth rate $\left(\mathrm{SGR}, \%\right.$ day $\left.^{-1}\right)$ & $1.51^{\mathrm{a}}$ & $1.22^{\mathrm{b}}$ & $1.24^{\mathrm{b}}$ & $1.19^{\mathrm{b}}$ & $1.02^{\mathrm{c}}$ & 0.08 & 0.020 \\
\hline Hepatosomatic index (HSI, \%) & 1.05 & 1.39 & 1.36 & 1.17 & 1.41 & 0.07 & 0.207 \\
\hline Protein efficiency ratio (PER, g gain g protein $^{-1}$ ) & $4.05^{\mathrm{a}}$ & $3.40^{\mathrm{b}}$ & $3.95^{\mathrm{ab}}$ & $3.69^{\mathrm{ab}}$ & $3.70^{\mathrm{ab}}$ & 0.11 & 0.138 \\
\hline
\end{tabular}

Differences between means were tested with Duncan's multiple range test.

Different superscripts in the same row indicate a significant difference $(P<0.05)$.

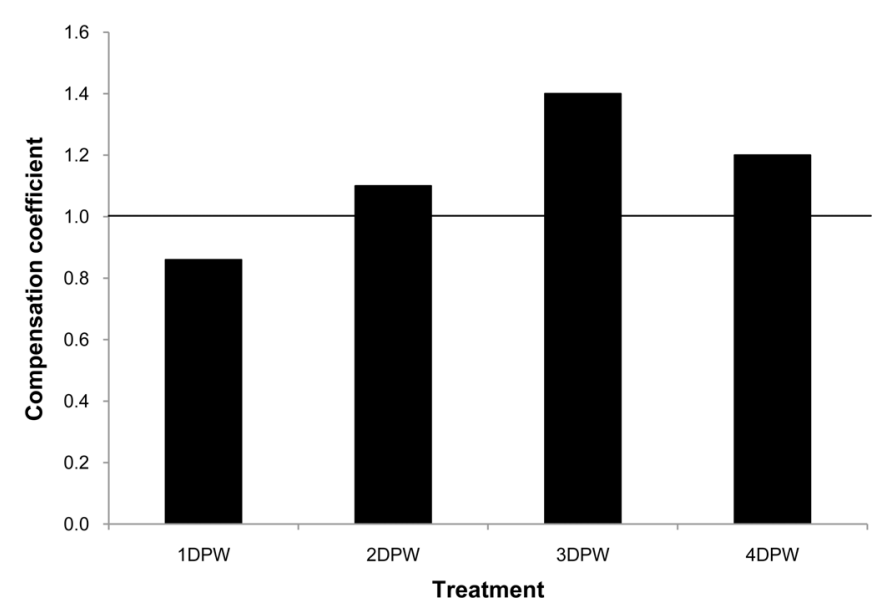

Fig. 1. Changes in compensation coefficient (CC) in juvenile yellow mystus subjected to various starvation and refeeding cycles. The values were calculated from three replicate experiments. CC $>1$ represents compensation.

\subsection{Carcass composition}

The carcass compositions, in terms of moisture, protein, lipid, ash and lipid/LBM, were not statistically different across the five feeding treatments (Table 3 ).

\subsection{Muscle quality}

Cyclical starvation and refeeding had no significant effects on RNA and protein concentrations in the white muscle of the reared fish (Table 3). The RNA/protein ratio was similar in the ODPW, 1DPW and 4DPW groups, while it had significantly lower values in both the 2DPW and 3DPW groups. The thermal transition properties of the major muscle proteins (including myosin, actin and sarcoplasmic protein) had similar characteristics across the five feeding treatments. The denaturation responses of the three proteins in the control group are depicted in Figure 4. The amounts of native myosin and actin, based on enthalpy response, did not differ between the feeding treatment groups (Table 3). The sarcoplasmic proteins differed only between the 1DPW and the 4DPW groups.

\section{Discussion}

Induced compensatory growth has been observed in a wide range of fish species when periodic feed starvation is followed by feeding to satiation, in other words with cyclical starvation and refeeding (Ali et al., 2003). In the current study, our results show that the juvenile yellow mystus can compensate for starvation on three consecutive days per week if fed to satiation on the remaining days, at least in terms of body weight, although the SGR was significantly lower than in the control ODPW group. Within the studied period, the other feeding treatment groups could not recover their loss of growth relative to the control group, as indicated by loss of body weight, SGR or PER. However, in a prolonged experiment, accelerated growth might dominate, as indicated by the $\mathrm{CC}$ analysis for the 2DPW and the 4DPW groups, but not for 1DPW. This value is considered proof of compensation growth, as observed in pikeperch, Sander lucioperca (Mattila et al., 2009) and rainbow trout, Oncorhynchus mykiss (Taşbozan et al., 2016). Bavčević et al. (2010) reported compensation in body weight of gilthead sea bream (Sparus aurata), but not length, under restriction and refeeding cycles. Our findings were contradictory to this, in that the length also increased along with fish weight, and the proportion between weight and length remained unchanged as indicated by $\mathrm{CF}$. Our findings, however, agree with the changes of weight, length and $\mathrm{CF}$ in juvenile whitefish (Coregonus lavaretus) that were not fed during weekends, and that were compared to fish fed every day (Känkänen and Pirhonen, 2009).

Liver weight correlates positively with the body weight of fish (Känkänen and Pirhonen, 2009), while the relative index (HSI) indicates the ratio of its mass and the body mass. Decreases in both liver mass and HSI are known in fish during periods of undernutrition and increases in both occur with the overcompensation or compensation when feeding restrictions are removed (Weatherley and Gill, 1981; Gaylord and Gatlin, 2000). Therefore, not having differences in HSI probably indicates that there was no malnutrition despite periodic feed starvation. Further analyses such as hematological parameters and liver histopathological examination could be used to assess this hypothesis. Generally, fish can adjust their behavior in response to energy reserves to optimize energy intake against the risk of starvation (van Dijk et al., 2002; Näslund and Johnsson, 2016). Considering the feed utilization parameters, 

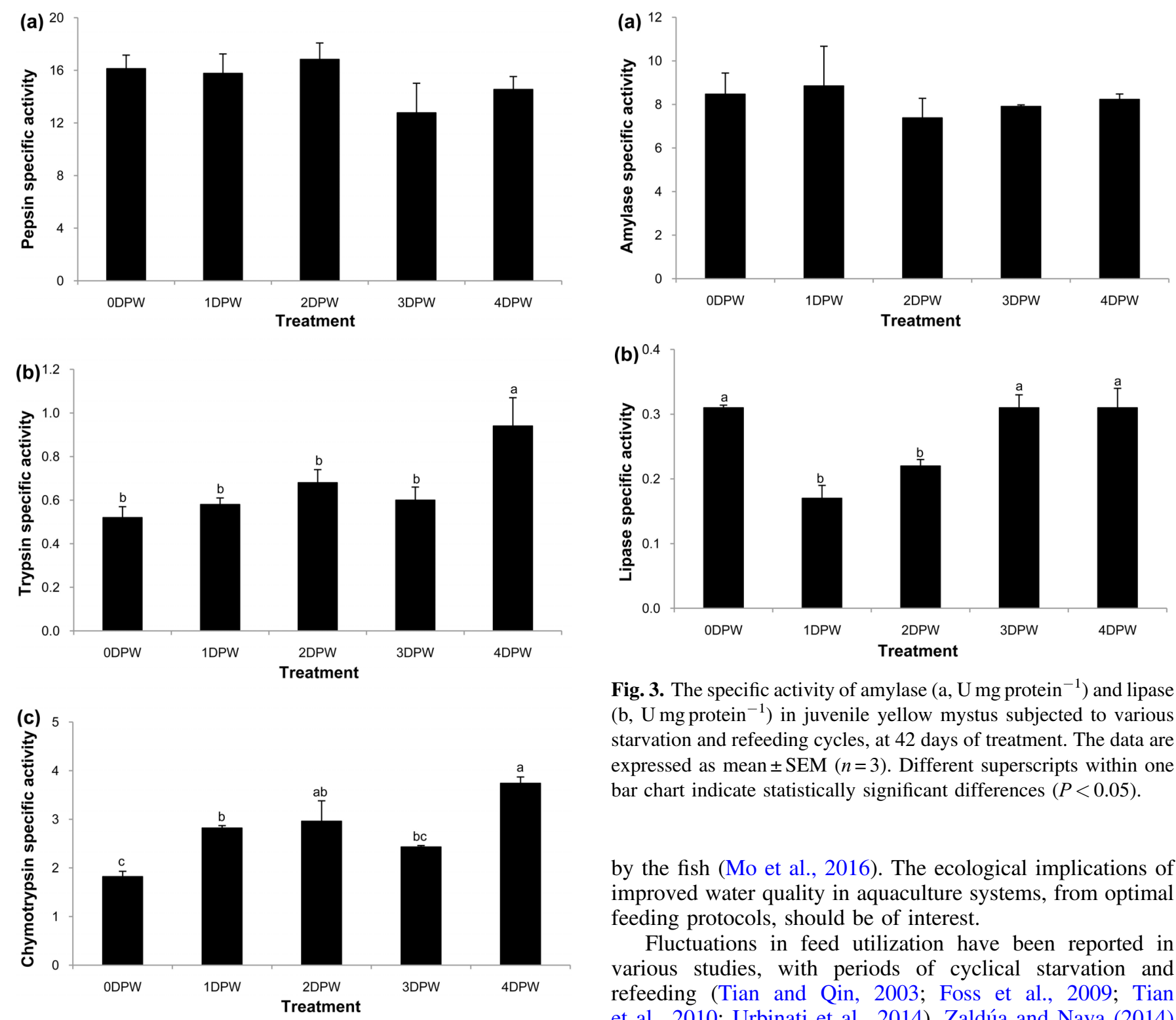

Fig. 3. The specific activity of amylase (a, $\mathrm{U} \mathrm{mg} \mathrm{protein}^{-1}$ ) and lipase (b, $\mathrm{U}$ mg protein ${ }^{-1}$ ) in juvenile yellow mystus subjected to various starvation and refeeding cycles, at 42 days of treatment. The data are expressed as mean \pm SEM $(n=3)$. Different superscripts within one bar chart indicate statistically significant differences $(P<0.05)$.

by the fish (Mo et al., 2016). The ecological implications of improved water quality in aquaculture systems, from optimal feeding protocols, should be of interest.

Fluctuations in feed utilization have been reported in various studies, with periods of cyclical starvation and refeeding (Tian and Qin, 2003; Foss et al., 2009; Tian et al., 2010; Urbinati et al., 2014). Zaldúa and Naya (2014)

Fig. 2. The specific activity of pepsin (a, $\left.\mathrm{mU} \mathrm{mg}_{\text {protein }}{ }^{-1}\right)$, trypsin (b, U mg protein ${ }^{-1}$ ) and chymotrypsin (c, $\mathrm{U} \mathrm{mg} \mathrm{protein}{ }^{-1}$ ) in juvenile yellow mystus subjected to various starvation and refeeding cycles, at 42 days of treatment. The data are expressed as mean $\pm \operatorname{SEM}(n=3)$. Different superscripts within one bar chart indicate statistically significant differences $(P<0.05)$.

the feeding treatments had no effects on FI, FCR or FER $(P>0.05)$. This indicates that the fish in the periodically feed starved groups ate more per meal in order to maintain their average FI. Moreover, based on our water management, this feeding schedule maintained the water quality, and all the quality parameters were within the standard requirements for fish farming (Zweig et al., 1999). The 4DPW treatment group had significantly reduced ammonia concentrations relative to the control. A possible mechanism for reducing ammonia excretion may be associated with significant upregulation of proteolytic activities, mainly trypsin and chymotrypsin, which reduce the amount of waste nitrogenous compounds excreted suggested that there is a progressive decrease of intestinal mass with starvation time and an increase of gut mass during refeeding, and these could involve changes in the enterocyte turnover rate and intestinal epithelial configuration. Observation of digestive functions through enzyme activities could help understand physiological acclimatization to a feeding regimen. Chan et al. (2008) and Pujante et al. (2015) reported no difference in the pepsin specific activity between groups of starved and refed tilapia (Oreochromis mossambicus), or of thick-lipped grey mullet (Chelon labrosus), whereas either the trypsin or chymotrypsin specific activity showed significant differences. Both these prior reports are in agreement with our observations in juvenile yellow mystus, suggesting that pepsin is less sensitive than trypsin and chymotrypsin to the feeding strategy (Rungruangsak-Torrissen et al., 2006).

About 40-50\% of ingested dietary proteins are digested in the intestine by trypsin (Eshel et al., 1993). This enzyme regulates its own activity and many zymogens. The highest activity of trypsin in the fish deprived 4DPW might indicate insufficient protein intake causing an excessive production 
Table 3. Carcass compositions and muscle quality of yellow mystus reared under various cyclical starvation and refeeding cycles.

\begin{tabular}{|c|c|c|c|c|c|c|c|}
\hline Parameter & 0DPW & 1DPW & 2DPW & 3DPW & 4DPW & SEM & $P$ value \\
\hline Moisture & 73.72 & 73.34 & 73.48 & 74.46 & 74.46 & 0.24 & 0.700 \\
\hline Crude lipid & 3.84 & 4.88 & 4.01 & 3.60 & 4.05 & 0.22 & 0.473 \\
\hline Crude ash & 5.05 & 5.21 & 4.39 & 5.02 & 4.46 & 0.17 & 0.397 \\
\hline \multicolumn{8}{|c|}{ Muscle quality (wet weight basis) } \\
\hline RNA $\left(\mu \mathrm{gg}^{-1}\right)$ & 574.93 & 593.26 & 457.65 & 536.15 & 565.94 & 23.84 & 0.268 \\
\hline Protein $\left(\mathrm{mg} \mathrm{g}^{-1}\right)$ & 209.80 & 211.92 & 241.97 & 236.05 & 226.96 & 6.38 & 0.267 \\
\hline $\mathrm{RNA} /$ protein ratio $\left(\mu \mathrm{g} \mathrm{mg}^{-1}\right)$ & $2.77^{\mathrm{ab}}$ & $3.20^{\mathrm{a}}$ & $2.34^{\mathrm{b}}$ & $2.37^{\mathrm{b}}$ & $2.74^{\mathrm{ab}}$ & 0.16 & 0.061 \\
\hline$\Delta \mathrm{H}_{\mathrm{Myosin}}\left(\mathrm{Jg}^{-1}\right)$ & 0.18 & 0.21 & 0.17 & 0.16 & 0.16 & $<0.01$ & 0.515 \\
\hline
\end{tabular}

Lipid/LBM is the ratio of lipids to the sum of protein and ash.

Differences between means were tested with Duncan's multiple range test.

Different superscripts in the same row indicate a significant difference $(P<0.05)$.

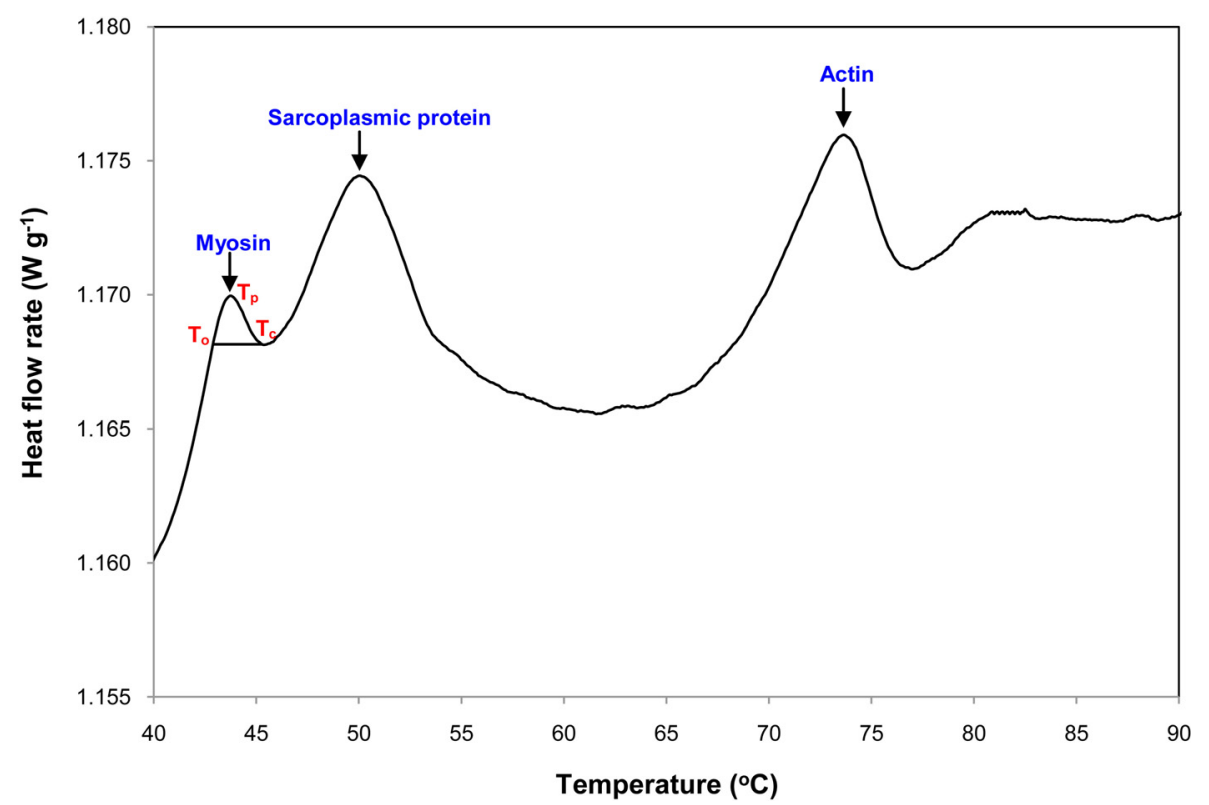

Fig. 4. The denaturation enthalpies of myosin, actin and sarcoplasmic protein in the white muscles of juvenile yellow mystus, shown for the control treatment only. $T_{0}=$ onset temperature, $T_{p}=$ peak temperature, and $T_{c}=$ conclusion temperature.

response. The fact that FI, FCR and PER were not affected by the cyclical starvation and refeeding (Morshedi et al., 2016) is due to the fish adapting in their efficient utilization of food (Wang et al., 1998). Moreover, protein intake is associated with growth by complicated mechanisms, suggesting that the effects of cyclical starvation and refeeding seen in trypsin activity alone should be small. On the other hand, no proteolytic enzyme activity was significantly reduced with a decreasing feed starvation period, suggesting that protein catabolism was well maintained or increased in the other treatment groups relative to the control. A similar type of response has been observed in juvenile roach (Rutilus rutilus caspicus) when feed deprived for 1-3 weeks and then refed (Abolfathi et al., 2012). As for chymotrypsin, this enzyme has different active sites than trypsin and responds to different dietary proteins. Its relatively high activity in the 1DPW and the 2DPW groups suggests that the various enzymes respond in individually different ways to control protein utilization. Elevated activity of this enzyme was associated with a slow growth rate in a study by Rungruangsak-Torrissen et al. (2006) and by Chan et al. (2008).

Since glucose is an essential energy source for a number of tissues, it is particularly important to maintain the levels throughout starvation (Romijn et al., 1990). The amylase 
specific activity was unaffected by feeding treatment, indicating that the juvenile fish had similar abilities for carbohydrate digestion. This digestive function relates to the maintenance of energy and is necessary for metabolic homeostasis. Our findings agree with the expression of amylase in rainbow trout (Furné et al., 2008) and in thicklipped grey mullet (Pujante et al., 2015). Generally, carnivorous fish diets contain abundant proteins and lipids, and high lipase activity contributes to successful digestion of the lipids in food (Chakrabarti et al., 1995). The rate of compensation in these treatment groups might be affected by lipid metabolism. Overall, it appears that trypsin, chymotrypsin and lipase are sensitive to cyclical starvation and refeeding and play important roles in utilizing nutrients. In terms of these enzymes' activities, our four experimental groups had different strategies to control their nutrient homeostasis. The successful growth compensation in the 3DPW group was enabled by maintaining the activities of the observed enzymes. The 4DPW group physiologically acclimatized to restricted dietary protein by controlling the activities of the key proteolytic enzymes, trypsin and chymotrypsin, to improve protein digestion. Yarmohammadi et al. (2013) suggested that lipids were the preferred nutrients for mobilization in juvenile Persian sturgeon (Acipenser persicus) during starvation periods. Therefore, increased activity of chymotrypsin in association with growth reduction, but with decreased lipase activity, indicate insufficient nutrients for growth in both the 1DPW and the 2DPW groups. However, the fish in both the 3DPW and 4DPW groups were higher in lipase activity than in 1DPW and 2DPW. Sacristán et al. (2014) proposed that with food absent for a long period and then refeeding, the de novo synthesis of digestive lipase would be stimulated, inhibiting the use of stored lipids as energy by intracellular lipase. Similar levels of lipase activity in the 3DPW and 4DPW groups as in the control ODPW group might be due to boosting of mechanisms that improved nutrient utilization.

The proximate composition of fish at the end of experiment was unaffected by treatment and similar to that of the control fish. This indicates that the juveniles can defend their proximate composition in the face of feed cyclical changes, and this aspect appears to be more important than accelerating growth, at least in some of the treatment groups. Similar proximate compositions between the deprived (one week starvation and two weeks subsequent refeeding) and control (continuous feeding) groups have been reported previously in gibel carp (Carassius auratus gibelio) and in Chinese longsnout catfish (Leiocassis longirostris) (Zhu et al., 2004). However, long-term starvation can significantly change the carcass composition of juvenile tongue sole, Cynoglossus semilaevis (Tian et al., 2010). Tian and Qin (2003) reported no treatment effects on protein, ash and moisture, but on lipid and lipid/LBM, in barramundi (Lates calcarifer) experiencing starvation and refeeding cycles. The decreased lipid/LBM was considered an indicator predictive of compensatory growth response, based on the lipostatic model (Jobling and Johansen, 1999). The unaffected lipid/LBM in our findings suggests that the observed compensatory growth of this species was unrelated to the lipostatic model.

White muscle is a reservoir for metabolism and protein growth (Carter et al., 1995). Therefore, the muscle quality parameters are more sensitive than the body composition to starvation-refeeding cycles, and show physiological changes. The fish with a higher growth rate had a lower RNA/protein ratio (Sunde et al., 2001; Thongprajukaew et al., 2013). Therefore, the high ratios in the $2 \mathrm{DPW}$ and the 3DPW treatment groups indicate superior protein synthesis compared to the 1DPW group. However, there were no differences in the RNA/protein ratio between the starvation treatments as compared to the control 0DPW group. van Dijk et al. (2005) reported no change in the RNA/protein ratio during 21 days of starvation in juvenile roach. A similar finding was also observed in juvenile rock carp (Procypris rabuidi) that were starved for 1, 2 and 3 days followed by refeeding (Yun et al., 2012). These findings indicate that the response in protein synthesis capacity (RNA/protein ratio) varies by fish species, and variations may also be expected in optimal cyclical starvation and refeeding intervals. Data on the thermal transition properties indicated the presence of some major proteins (actin, myosin and sarcoplasmic protein) in the muscle. The $\Delta \mathrm{H}$ value relates to the amount of native proteins that require the most energy for full denaturing (Matos et al., 2011). The similarity of $\Delta \mathrm{H}$ values indicates normal physical exercise across the feeding regimens (Thongprajukaew et al., 2015).

\section{Conclusions}

The current study investigated juvenile yellow mystus (Hemibagrus nemurus) subjected to periodic feed starvationrefeeding cycles that could provide farmers savings in terms of labor costs. Starving the fish for three consecutive days per week and then refeeding on the remaining days induced clear growth compensation, sufficient for competitive growth of the juvenile fish. This choice was near optimal, as decreasing the number of weekly feeding days gave inferior growth, except for the control case with regular daily feeding. Partial compensation by accelerated growth was also observed in fish fed two or four days weekly. Further period choices in alternating between starving and refeeding might also improve the compensation. The findings from this study provide an alternative feeding schedule for the aquaculture production of yellow mystus, with potential benefits to labor management.

Acknowledgements. This work was partially supported by the Department of Bioscience, Faculty of Sciences and Fisheries Technology, Rajamangala University of Technology Srivijaya, and the Department of Applied Science, Faculty of Science, Prince of Songkla University (PSU). The authors would like to thank Assoc. Prof. Dr. Seppo Karrila for the proofreading of a draft, and the Publication Clinic of the PSU for help in manuscript preparation.

\section{References}

Abolfathi M, Hajimoradloo A, Ghorbani R, Zamani A. 2012. Effect of starvation and refeeding on digestive enzyme activities in juvenile roach, Rutilus rutilus caspicus. Comp Biochem Physiol 161A: 166-173.

Ali M, Nicieza A, Wootton RJ. 2003. Compensatory growth in fishes: a response to growth depression. Fish Fish 4: 147-190. 
Amornsakun T, Hassan AB, Ambak AB, Chiayvareesajja S. 1998. The culture of green catfish, Mystus nemurus (Cuv. \& Val.). I: Feed and feeding scheme of larvae and juveniles. Songklanakarin J Sci Technol 20: 379-384.

AOAC. 2005. Official methods of analysis, 18th ed. Washington, DC: Association of Official Analytical Chemists.

APHA, AWWA, WPCF. 1998. Standard methods for the examination of water and wastewater, 20th ed. Washington, DC: American Public Health Association, American Water Works Association, Water Pollution Control Federation.

Areekijseree M, Engkagul A, Kovitvadhi U, et al. 2004. Temperature and $\mathrm{pH}$ characteristics of amylase and proteinase of adult freshwater pearl mussel, Hyriopsis (Hyriopsis) bialatus Simpson 1900. Aquaculture 234: 575-587.

Bavčević L, Klanjšček T, Karamarko V, Aničić I, Legović T. 2010. Compensatory growth in gilthead sea bream (Sparus aurata) compensates weight, but not length. Aquaculture 301: 57-63.

Carter CG, He ZY, Houlihan DF, McCarthy ID, Davidson I. 1995. Effect of feeding on the tissue free amino acid concentrations in rainbow trout (Oncorhynchus mykiss Walbaum). Fish Physiol Biochem 14: 153-164.

Chakrabarti I, Gani MDA, Chaki KK, Sur R, Misra KK. 1995. Digestive enzymes in 11 freshwater teleost fish species in relation to food habit and niche segregation. Comp Biochem Physiol 112A: 167-177.

Chan CR, Lee DN, Cheng YH, Hsieh DJY, Weng CF. 2008. Feed deprivation and refeeding on alterations of proteases in tilapia Oreochromis mossambicus. Zool Stud 47: 207-214.

Eshel A, Lindner P, Smirnoff P, Newton S, Harpaz S. 1993. Comparative study of proteolytic enzymes in the digestive tracts of the European sea bass and hybrid striped bass reared in freshwater. Comp Biochem Physiol 106A: 627-634.

Foss A, Imsland AK, Vikingstad E, et al. 2009. Compensatory growth in Atlantic halibut: effect of starvation and subsequent feeding on growth, maturation, feed utilization and flesh quality. Aquaculture 290: 304-310.

Furné M, García-Gallego M, Hidalgo MC, et al. 2008. Effect of starvation and refeeding on digestive enzyme activities in sturgeon (Acipenser naccarii) and trout (Oncorhynchus mykiss). Comp Biochem Physiol 149A: 420-425.

Gaylord TG, Gatlin III DM. 2000. Assessment of compensatory growth in channel catfish Ictalurus punctatus R. and associated changes in body condition indices. J World Aquac Soc 31: 326-336.

Heide A, Foss A, Stefansson SO, et al. 2006. Compensatory growth and fillet crude composition in juvenile Atlantic halibut: effects of short term starvation periods and subsequent feeding. Aquaculture 261: 109-117.

Jobling M, Johansen SJS. 1999. The lipostat, hyperphagia and catchup growth. Aquac Res 30: 473-478.

Jobling M, Meløy OH, Dos Santos J, Christiansen B. 1994. The compensatory growth response of the Atlantic cod: effects of nutritional history. Aquac Int 2: 75-90.

Känkänen M, Pirhonen J. 2009. The effect of intermittent feeding on feed intake and compensatory growth of whitefish Coregonus lavaretus L. Aquaculture 288: 92-97.

Kottelat M. 1998. Fishes of the Nam Theun and Xe Bangfai basins, Laos, with diagnoses of twenty-two new species (Teleostei: Cyprinidae, Balitoridae, Cobitidae, Coiidae and Odontobutidae). Ichthyol Explor Freshw 9: 1-128.

Lowry OH, Rosenbrough NJ, Farr AL, Randall RJ. 1951. Protein measurement with the Folin phenol reagent. J Biol Chem 193: 265-275.
Matos E, Silva TS, Tiago T, Aureliano M, Dinis MT, Dias J. 2011. Effect of harvesting stress and storage conditions on protein degradation in fillets of farmed gilthead seabream (Sparus aurata): a differential scanning calorimetry study. Food Chem 126: 270-276.

Mattila J, Koskela J, Pirhonen J. 2009. The effect of the length of repeated feed deprivation between single meals on compensatory growth of pikeperch Sander lucioperca. Aquaculture 296: 65-70.

Mo WY, Lau RSS, Kwok ACK, Wong MH. 2016. Use of soybean meal and papain to partially replace animal protein for culturing three marine fish species: fish growth and water quality. Environ Pollut. DOI:10.1016/j.envpol.2016.07.059.

Morshedi V, Kochanian P, Bahmani M, et al. 2016. Cyclical shortterm starvation and refeeding provokes compensatory growth in sub-yearling Siberian sturgeon, Acipenser baerii Brandt, 1869. Anim Feed Sci Technol. DOI:10.1016/j.anifeedsci.2016.10.005.

Näslund J, Johnsson J. 2016. State-dependent behavior and alternative behavioral strategies in brown trout (Salmo trutta L.) fry. Behav Ecol Sociobiol 70: 2111-2125.

Ng HH, Rainboth W. 1999. The bagrid catfish genus Hemibagrus (Teleostei: Siluriformes) in central Indochina with a new species from the Mekong River. Raffles Bull Zool 47: 555-576.

Nicieza A, Álvarez D. 2009. Statistical analysis of structural compensatory growth: how can we reduce the rate of false detection? Oecologia 159: 27-39.

Pujante IM, Martos-Sitcha JA, Moyano FJ, Ruiz-Jarabo I, MartínezRodríguez G, Mancera JM. 2015. Starving/refeeding processes induce metabolic modifications in thick-lipped grey mullet (Chelon labrosus Risso 1827). Comp Biochem Physiol 180B: $57-67$.

Rainboth WJ. 1996. FAO Species identification field guide for fishery purposes. Fishes of the Cambodian Mekong. Rome: FAO.

Romijn JA, Godfried MH, Hommes MJT, Endert E, Sauerwein HP. 1990. Decreased glucose oxidation during short-term starvation. Metabolism 39: 525-530.

Rungruangsak K, Utne F. 1981. Effect of different acidified wet feeds on protease activities in the digestive tract and on growth rate of rainbow trout (Salmo gairdneri Richardson). Aquaculture 22: $67-79$.

Rungruangsak-Torrissen K. 2007. Digestive efficiency, growth and qualities of muscle and oocyte in Atlantic salmon (Salmo salar L.) fed on diets with krill meal as an alternative protein source. J Food Biochem 31: 509-540.

Rungruangsak-Torrissen K, Moss R, Andresen LH, Berg A, Waagbo R. 2006. Different expressions of trypsin and chymotrypsin in relation to growth in Atlantic salmon (Salmo salar L.). Fish Physiol Biochem 32: 7-23.

Sacristán HJ, Nolasco-Soria H, López Greco LS. 2014. Effect of attractant stimuli, starvation period, and food availability on digestive enzymes in the redclaw crayfish Cherax quadricarinatus (Parastacidae). Aquat Biol 23: 87-99.

Skipnes D, der Plancken IV, Loey AV, Hendrickx ME. 2008. Kinetics of heat denaturation of proteins from farmed Atlantic cod (Gadus morhua). J Food Eng 85: 51-58.

Sunde J, Taranger GL, Rungruangsak-Torrissen K. 2001. Digestive protease activities and free amino acids in white muscle as indicators for feed conversion efficiency and growth rate in Atlantic salmon (Salmo salar L.). Fish Physiol Biochem 25: 335-345.

Supannapong P, Pimsalee T, A-komol T, et al. 2008. Digestive enzymes and in vitro digestibility of different species of phytoplankton for culture of the freshwater pearl mussel, Hyriopsis (Hyriopsis) bialatus. Aquac Int 16: 437-453. 
Taşbozan O, Emre Y, Gökce MA, Erbaş C, Özcan F, Kıvrak E. 2016. The effects of different cycles of starvation and re-feeding on growth and body composition in rainbow trout (Oncorhynchus mykiss, Walbaum, 1792). J Appl Ichthyol 32: 583-588.

Thalathiah S, Abas OF, Ibrahim T. 1988. First successful attempt to induce breed Mystus nemurus $(\mathrm{C} \& \mathrm{~V})$ at Batu Berendam, Melaka. In: Proceedings of the 11th Malaysian Society of Animal Production Annual Conference. Serdang: Malaysian Society of Animal Production, pp. 189-193.

Thalathiah S, Ibrahim T, Mansor A. 1992. Induced spawning of Mystus nemurus (C \& V) using heteroplastic pituitary extract, HCG and an analog of LHRH. In: Proceedings of Fisheries Research Seminar 1989. Kuala Lumpur: Department of Fisheries, pp. 185-188.

Tian X, Qin JG. 2003. A single phase of food deprivation provoked compensatory growth in barramundi Lates calcarifer. Aquaculture 224: 169-179.

Tian X, Fang J, Dong S. 2010. Effects of starvation and recovery on the growth, metabolism and energy budget of juvenile tongue sole (Cynoglossus semilaevis). Aquaculture 310: 122-129.

Thongprajukaew K, Kovitvadhi U, Kovitvadhi S, Engkagul A, Rungruangsak-Torrissen K. 2013. Evaluation of growth performance and nutritional quality of diets using enzymatic markers and in vitro digestibility in Siamese fighting fish (Betta splendens Regan, 1910). Afr J Biotechnol 12: 1689-1702.

Thongprajukaew K, Rodjaroen S, Yoonram K, et al. 2015. Effects of dietary modified palm kernel meal on growth, feed utilization, radical scavenging activity, carcass composition and muscle quality in sex reversed Nile tilapia (Oreochromis niloticus). Aquaculture 439: 45-52.

Urbinati EC, Sarmiento SJ, Takahashi LS. 2014. Short-term cycles of feed deprivation and refeeding promote full compensatory growth in the Amazon fish matrinxã (Brycon amazonicus). Aquaculture 433: 430-433. van Dijk PLM, Staaks G, Hardewig I. 2002. The effect of fasting and refeeding on temperature preference, activity and growth of roach, Rutilus rutilus. Oecologia 130: 496-504.

van Dijk PLM, Hardewig I, Hölker F. 2005. Energy reserves during food deprivation and compensatory growth in juvenile roach: the importance of season and temperature. J Fish Biol 66: 167-181.

Wang N, Hayward RS, Noltie DB. 1998. Effect of feeding frequency on food consumption, growth, size variation, and feeding pattern of age-0 hybrid sunfish. Aquaculture 165: 261-267.

Weatherley AH, Gill HS. 1981. Recovery growth following periods of restricted rations and starvation in rainbow trout Salmo gairdneri Richardson. J Fish Biol 18: 195-208.

Winkler UK, Stuckmann M. 1979. Glycogen, hyaluronate and some other polysaccharides greatly enhance the formation of exolipase by Serratia marcescens. J Bacteriol 138: 663-670.

Yarmohammadi M, Shabani A, Pourkazemi M, et al. 2013. Effects of starvation and re-feeding on compensatory growth performance, plasma metabolites and IGF-I gene expression of Persian sturgeon (Acipenser persicus, Borodin 1897). Iranian J Fish Sci 12: 465-483.

Yun L, Zhi-Qiang Z, Ortegón O, Qin Y. 2012. Effects of short-term starvation and refeeding on the survival, and RNA/DNA and RNA/protein ratios in rock carp (Procypris rabuadi) larvae. Acta Hydrobiol. Sin. 36: 674-681.

Zaldúa N, Naya DE. 2014. Digestive flexibility during fasting in fish: a review. Comp Biochem Physiol 169A: 7-14.

Zhu X, Xie S, Zou Z, et al. 2004. Compensatory growth and food consumption in gibel carp, Carassius auratus gibelio, and Chinese longsnout catfish, Leiocassis longirostris, experiencing cycles of feed deprivation and refeeding. Aquaculture 241: 235-247.

Zweig RD, Morton JD, Stewart MM. 1999. Source water quality for aquaculture: a guide for assessment. Washington, DC: The World Bank.

Cite this article as: Thongprajukaew K, Rodjaroen S. 2017. Intermittent feeding induces compensatory growth of juvenile yellow mystus (Hemibagrus nemurus). Aquat. Living Resour. 30: 6 